\title{
Further studies on the effect of radiation during the storage of frozen 8-cell mouse embryos at $-196^{\circ} \mathrm{C}$
}

\author{
P. H. Glenister, D. G. Whittingham* and Mary F. Lyon \\ M.R.C. Radiobiology Unit, Harwell, Didcot, Oxon OXII ORD and *M.R.C. Experimental \\ Embryology and Teratology Unit, Woodmansterne Road, Carshalton, Surrey SMS 4EF, U.K.
}

\begin{abstract}
Summary. Frozen 8-cell mouse embryos were treated with radiation doses of $0,10,50$, 100 or $200 \mathrm{cGy} \gamma$-rays at a dose rate of $\simeq 5 \mathrm{cGy} /$ day. After thawing the embryos were scored for normal morphological appearance and for development to morulae and blastocysts after $24 \mathrm{~h}$ in culture. Embryos from each treatment were then separately transferred to the uteri of pseudopregnant foster mothers which were killed at Day 14 of pregnancy. There was no effect of radiation on morphological appearance, development to morulae and blastocysts, implantation rate, or on the ratio of live fetuses to the number of transferred embryos.

As there appeared to be no detrimental effect of up to $200 \mathrm{cGy}$ on frozen 8-cell mouse embryos and, as this is the equivalent of $\simeq 2000$ years of background radiation, it is concluded that normal levels of background radiation would not be a hazard to the long-term storage of mammalian embryos.
\end{abstract}

\section{Introduction}

In previous experiments designed to examine the cumulative effects of background radiation during the storage of mouse embryos at $-196^{\circ} \mathrm{C}$ (Whittingham, Lyon \& Glenister, 1977; Lyon, Whittingham \& Glenister, 1977) there appeared to be a decrease in viability, as measured by the ability of the embryos to develop to the blastocyst stage in vitro, after storage for about 5 years at the higher radiation doses (Lyon, Glenister \& Whittingham, 1981). This was a surprising finding since even the highest radiation dose was relatively small (reported as $\sim 64 \mathrm{cGy}$ ) and well below the dose of $\mathrm{X}$-irradiation that prevented $50 \%$ of 8 -cell mouse embryos developing to the blastocyst stage when administered at normal temperatures (388-473 R: Goldstein, Spindle \& Pedersen, 1975; Dufrain, 1976). It became even more surprising when it was realized that, owing to circumstances beyond our control, the actual radiation doses received were lower than reported in our paper. In addition, low temperature and cryoprotective agents such as dimethylsulphoxide $\left(\mathrm{Me}_{2} \mathrm{SO}\right)$ and glycerol are known to afford some protection against radiation damage (Ashwood-Smith, 1967; Nias \& Ebert, 1969). Damage induced in somatic $\mathrm{CHO}$ cells $\mathrm{X}$-irradiated at $-196^{\circ} \mathrm{C}$ in the presence of $10 \% \mathrm{Me}_{2} \mathrm{SO}$ was reduced by a factor of 3.7 when compared with similar cells irradiated at $+22^{\circ} \mathrm{C}$ (Ashwood-Smith \& Grant, 1977). Indirect evidence has shown that preimplantation mouse embryos are capable of repairing DNA damage induced by ultraviolet light but the amount of damage that can be repaired is unknown (Pedersen \& Brandiff, 1981). It is possible that the activity of repair enzymes is reduced by freezing and thawing and, irrespective of the radioprotection afforded by low temperature and cryoprotectants, there is insufficient enzyme activity to repair effectively the radiation damage accumulated during storage. 
This apparent effect on the ability to develop to the blastocyst stage in vitro was the only effect of radiation detected in the previous studies. Other criteria examined were: post-implantation development to fetuses and liveborn, breeding tests on the liveborn young to assess their fertility and to look for mutations amongst their offspring, chromosome preparations from the testes of the male liveborn and dissection of female liveborn in mid-pregnancy to detect dominant lethal mutations (Lyon et al., 1981).

The major uncertainty arising from the earlier experiments is whether the decrease in viability observed at the higher radiation doses was due to radiation per se or some other uncontrolled factor. In an attempt to solve this problem, a further short-term experiment was carried out to examine the survival of 8-cell mouse embryos after exposure at $-196^{\circ} \mathrm{C}$ to various doses of $\gamma$-rays administered at a dose rate of $\sim 5 \mathrm{cGy} /$ day.

\section{Materials and Methods}

\section{Embryo collection}

Embryos were obtained from 6-8-week-old $3 \mathrm{H} 1\left(\mathrm{~F}_{1}, \mathrm{C} 3 \mathrm{H} / \mathrm{HeH} \times 101 / \mathrm{H}\right)$ hybrid mice which were induced to superovulate with gonadotrophins (for details see Biggers, Whitten \& Whittingham, 1971). After the injection of hCG, the females were mated with $3 \mathrm{H} 1 \mathrm{males}$ and 8-cell embryos were flushed from the excised oviducts 3 days later with a Hepes-buffered embryo culture medium (M2: Quinn, Barros \& Whittingham, 1982). At each collection the embryos from all females were pooled and washed through several changes of Medium M2 (2 ml/wash). Finally, 30 embryos were transferred to each glass ampoule $(2 \mathrm{ml}$ capacity; Jencons, Leighton Buzzard LU7 8UA, U.K.) containing $0.15 \mathrm{ml}$ Medium M2 and the ampoules were then placed in an icebath at $0^{\circ} \mathrm{C}$.

\section{Freezing and thawing}

The embryos were frozen and thawed by the 'rapid' method previously described (Whittingham, Wood, Farrant, Lee \& Halsey, 1979). After holding the embryos for $15 \mathrm{~min}$ at $0^{\circ} \mathrm{C}$, $0.15 \mathrm{ml} 3 \mathrm{M}$-dimethylsulphoxide was added to achieve a final concentration for cryoprotection of $1.5 \mathrm{M}-\mathrm{Me}_{2} \mathrm{SO}$. The ampoules were sealed and $15 \mathrm{~min}$ later transferred to a 'seeding' bath at $-9^{\circ} \mathrm{C}$. After $2 \mathrm{~min}$ in the seeding bath, ice formation was induced in the samples by sharply tapping the ampoules with metal forceps. The samples were then transferred to a cooling bath at $-6^{\circ} \mathrm{C}$ and they were cooled at rates ranging between 0.3 and $0.6^{\circ} \mathrm{C}$ per min. On reaching $-35^{\circ} \mathrm{C}$ the ampoules were plunged directly into liquid nitrogen for storage. All samples were thawed rapidly $\left(\sim 500^{\circ} \mathrm{C} / \mathrm{min}\right)$ by agitating the ampoules in a water bath at $40^{\circ} \mathrm{C}$. As soon as all the ice had disappeared the ampoules were placed on the bench at room temperature for $5 \mathrm{~min}$ before adding $1 \mathrm{ml}$ Medium M2 to each ampoule. The embryos were recovered, washed through several changes of Medium M2 and placed in drops of embryo culture medium (No. 16: Whittingham, 1971) overlaid with paraffin oil. They were cultured for $20-24 \mathrm{~h}$ at $37^{\circ} \mathrm{C}$ in an atmosphere of $5 \% \mathrm{CO}_{2}$ in air.

\section{Radiation exposure during storage}

During storage in liquid nitrogen the embryos were irradiated from a gamma source $\left({ }^{60} \mathrm{Co}\right)$ at a dose rate of $5.14 \mathrm{cGy} /$ day. The ampoules from each embryo collection were randomly allocated to one of 5 different total doses of $\gamma$-radiation $(0,10,50,100$ and $200 \mathrm{cGy} \gamma$-rays). After receiving the appropriate dose of radiation, the ampoules were removed from the radiation field and stored at normal levels of background radiation until thawed. The total length of storage at $-196^{\circ} \mathrm{C}$ varied between 5 and 8 months. 
Embryo recovery and culture

Thawing took place on 3 occasions over a period of 14 days. The ampoules were coded according to the dose of radiation, to avoid any possible bias in scoring embryos after recovery, culture and transfer. After thawing, the morphological appearance of the embryos was recorded, i.e. the number normal, damaged (1 or more blastomeres lysed), swollen or totally degenerated. After $20-24 \mathrm{~h}$ in culture the number of embryos reaching the morula and blastocyst stages was recorded. At this time the embryos from ampoules with the same code were pooled together in Medium M2 and held at room temperature in preparation for transfer.

\section{Embryo transfer}

Mature $3 \mathrm{H} 1$ females were naturally mated with sterile males (carrying the translocation $\mathrm{T} 145 \mathrm{H}$ ) and between 4 and 8 embryos were transferred to each uterine horn on the afternoon of the 3rd day of pseudopregnancy (Day 1 is the day on which the vaginal plug is found). Each female received embryos from only one dose level of radiation. All females were killed on Day 14 of gestation and the numbers of normal live fetuses, dead fetuses and resorbing implantation sites (moles) were recorded.

\section{Statistical analysis}

After decoding, the data on embryonic survival after freezing and thawing, culture and transfer were compared by $\chi^{2}$ analysis to test for homogeneity within and between each radiation dose and each thawing time.

\section{Results}

Over a period of 3 months 12008 -cell embryos from 10 separate collections were frozen and stored at $-196^{\circ} \mathrm{C}$ in glass ampoules each containing 30 embryos. Within 3-4 months of the completion of $\gamma$-irradiation the samples were thawed on 3 separate occasions over a 2 -week period. Table 1 summarizes the recovery and development in vitro of frozen-thawed 8-cell embryos after exposures to the different doses of $\gamma$-irradiation during storage. Of the 1200 embryos (40 samples) thawed, 1110 embryos $(93 \%)$ were recovered and $723(60 \%)$ appeared morphologically normal when placed in culture after removal of the cryoprotective agent. A total of $794(66 \%)$ had reached the morula or early blastocyst stage $24 \mathrm{~h}$ later. The slight increase in the number of embryos reaching the morula and blastocyst stages was due to the inclusion of embryos which originally appeared swollen after recovery and embryos which had only lost 1 or 2 blastomeres during freezing and thawing. There

Table 1. Survival and development in vitro of frozen-thawed 8-cell mouse embryos after exposure to various doses of $\gamma$-irradiation during storage at $-196^{\circ} \mathrm{C}$

\begin{tabular}{ccccc}
\hline $\begin{array}{c}\text { Radiation } \\
\text { dose (cGy) }\end{array}$ & $\begin{array}{c}\text { No. of ampoules* } \\
\text { thawed }\end{array}$ & $\begin{array}{c}\text { No. of embryos } \\
\text { recovered (\%) }\end{array}$ & $\begin{array}{c}\text { No. of embryos } \\
\text { normal at } \\
\text { recovery (\%) }\end{array}$ & $\begin{array}{c}\text { No. of morulae and } \\
\text { blastocysts after } \\
\text { 24 h in culture (\%) }\end{array}$ \\
\hline 0 & 8 & $225(93 \cdot 8)$ & $135(56 \cdot 3)$ & $160(66 \cdot 7)$ \\
10 & 8 & $223(92 \cdot 9)$ & $142(59 \cdot 2)$ & $151(62 \cdot 9)$ \\
50 & 8 & $222(92 \cdot 5)$ & $147(61 \cdot 3)$ & $157(65 \cdot 4)$ \\
100 & 8 & $223(92 \cdot 9)$ & $155(64 \cdot 6)$ & $172(71 \cdot 7)$ \\
200 & 8 & $217(90 \cdot 4)$ & $144(60 \cdot 2)$ & $154(64 \cdot 2)$ \\
\hline
\end{tabular}

* Each ampoule contained 30 8-cell embryos.

All percentages calculated from total no. of embryos originally frozen. 
Table 2. Post-implantation development of frozen-thawed 8-cell mouse embryos, exposed to different doses of $\gamma$-irradiation during storage, and cultured for $20-24 \mathrm{~h}$ before transfer to Day-3 pseudopregnant recipients

\begin{tabular}{|c|c|c|c|c|}
\hline \multirow{3}{*}{$\begin{array}{l}\text { Radiation } \\
\text { dose (cGy) }\end{array}$} & \multirow{3}{*}{$\begin{array}{l}\text { No. of embryos } \\
\text { transferred to } \\
\text { pregnant recipients } \\
\text { (no. of pregnant } q \text { ) }\end{array}$} & \multicolumn{3}{|c|}{ Examination on Day 14 of gestation } \\
\hline & & & & No. of live fetuses \\
\hline & & implantations $(\%) \dagger$ & live fetuses $(\%) \dagger$ & no. of implantations \\
\hline 0 & $148(12)$ & $130(87.8)$ & $81(54 \cdot 7)$ & $62 \cdot 3$ \\
\hline 10 & $151(12)$ & $119(78 \cdot 8)$ & $84(55 \cdot 6)$ & $70 \cdot 6$ \\
\hline 50 & $160(13)$ & $147(91.9)$ & $98(61 \cdot 3)$ & $66 \cdot 7$ \\
\hline 100 & $154(13)^{*}$ & $135(87 \cdot 7)$ & $82(53.2)$ & $60 \cdot 7$ \\
\hline 200 & 147 (12) & $140(95 \cdot 2)$ & $80(54 \cdot 4)$ & $57 \cdot 1$ \\
\hline
\end{tabular}

* In addition one recipient, which received 14 embryos, failed to become pregnant.

† Percentages calculated from no. of embryos transferred.

was no evidence to suggest that survival or subsequent development to the morula and blastocyst stages was affected by the amount of radiation given during storage. In addition, survival and development in vitro were not related to the separate freezing and thawing times.

The post-implantation development of embryos from the various treatments after transfer to pseudopregnant recipients is summarized in Table 2. As many embryos as possible were transferred, but the numbers were limited by the availability of recipients. Also, in the $50 \mathrm{cGy}$ group, 3 embryos, initially classified as slightly abnormal, cavitated during the holding time on the bench and were deemed fit for transfer.

A total of 774 embryos was transferred to 63 pseudopregnant recipients; $62(98 \%)$ females containing a total of $673(89 \%)$ implantations were examined on Day 14 of gestation and $425(56 \%)$ normal live fetuses were dissected from the implantation sites. Again, the dose of radiation did not affect the proportion of transferred embryos developing into normal live fetuses at 14 days gestation. Post-implantation development was also unrelated to the time of thawing. When the proportion of live fetuses to the total number of implantation sites was compared, the number of embryos lost during early post-implantation appeared to increase with increasing radiation dose, i.e. from 29 to $43 \%$ between 10 and $200 \mathrm{cGy}$. However, since the loss in the control unirradiated group was at an intermediate level ( $38 \%$ ) it is doubtful whether this decrease in viability was due to the effects of radiation. Statistical analysis showed that the 5 observations were satisfactorily homogeneous $\left(\chi_{4}^{2}=6 \cdot 16 ; P=0 \cdot 19\right)$.

In Text-fig. 1 , a summary is given of the proportion of embryos originally frozen surviving to the morula and blastocyst stages in vitro, implanting, and developing to live fetuses at Day 14 of
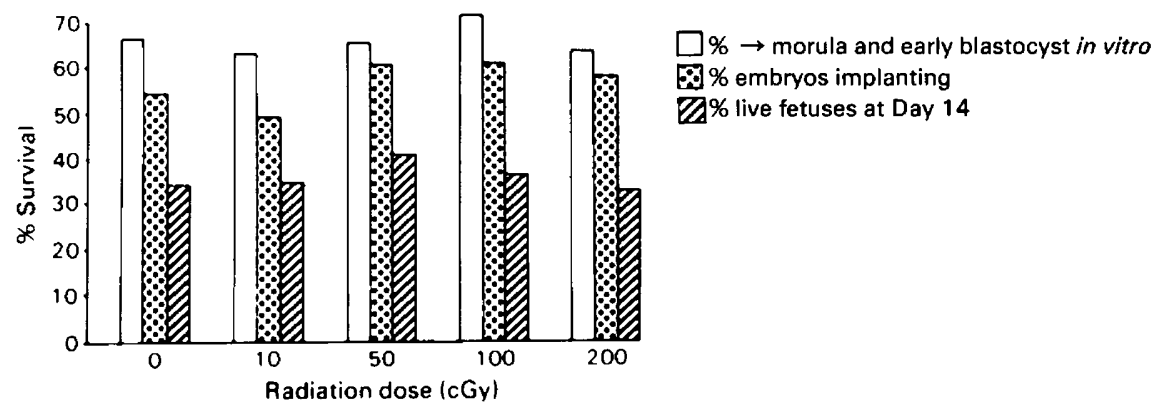

Text-fig. 1. Survival of 8-cell mouse embryos after exposure to various doses of $\gamma$ radiation during storage at $-196^{\circ} \mathrm{C}$ and expressed as a percentage of the number of embryos originally frozen and thawed at each dose (240 embryos per dose). 
gestation after transfer. About $35 \%$ of the total number of embryos frozen in all treatments developed into normal live fetuses and there was no significant difference in proportions surviving at each radiation dose.

\section{Discussion}

The irradiation of 8-cell mouse embryos during storage at $-196^{\circ} \mathrm{C}$ with doses of up to $200 \mathrm{cGy}$ had no adverse effect on the subsequent survival of the thawed embryos. The reason for the decrease in survival of embryos stored for about 5 years at $-196^{\circ} \mathrm{C}$ and receiving 4.5 and 42 cGy of $\gamma$ irradiation is puzzling (Lyon et al., 1981): it may have been due to uncontrolled factors resulting from the long time course of the experiment or to the decrease in the activity of DNA repair enzymes during prolonged storage. Since all biological activity in cells ceases below $-130^{\circ} \mathrm{C}$ it seems unlikely that embryos would deteriorate during prolonged storage at $-196^{\circ} \mathrm{C}$. In the previous study (Lyon et al., 1981), it is possible that a larger proportion of embryos was frozen at a stage of the cell cycle more susceptible to radiation damage. Dufrain \& Casarett (1975) have shown an increased sensitivity to radiation between the second and third cleavage division and a similar sensitivity may occur between the third and fourth cleavages. However, the low doses of radiation that were used in the long-term studies and the increased radioprotection afforded to cells during low-temperature storage (Ashwood-Smith \& Grant, 1977) would make it extremely difficult to measure any minor changes in radiosensitivity occurring between cleavage divisions in embryos stored at $-196^{\circ} \mathrm{C}$.

In the present study, the rapid freezing and thawing method was used (Whittingham et al., 1979) and the embryos were stored in sealed glass ampoules instead of screw-cap plastic ampoules. It is possible that the increased amount of water remaining in the embryos after rapid freezing may have decreased the sensitivity of embryos to radiation, although for seeds stored at temperatures above $0^{\circ} \mathrm{C}$ susceptibility to radiation damage is greater in the hydrated form than when they are dehydrated (Roberts, 1972). Glass will provide a small amount of protection against radiation but, more significantly, the survival of embryos after freezing and thawing in glass ampoules is much higher than in plastic ampoules, as shown previously (Whittingham, 1976). This probably accounts for the overall increase in survival rates to the morula and blastocyst stages in vitro and the number of implantations and live fetuses after transfer (Text-fig. 1) when compared with the long-term study (Whittingham et al., 1977; Lyon et al., 1981).

Assuming that the background level of radiation at Harwell is $\simeq 0.1 \mathrm{cGy} /$ year, embryos irradiated at the highest dose ( $200 \mathrm{cGy})$ received the equivalent of 2000 years of background radiation. Since no evidence of radiation damage was detected at this dose in the present study and it seems unlikely that the decreased viability observed at low radiation doses in the earlier longterm study was due to radiation, it is concluded that normal background radiation would not be detrimental to the long-term storage of mammalian embryos.

We are very grateful to $\mathrm{Mr} \mathbf{M}$. Corp for irradiations.

\section{References}

Ashwood-Smith, M.J. (1967) Radioprotective and cryoprotective properties of dimethylsulphoxide in cellular systems. Ann. N.Y. Acad. Sci. 141, 45-62.

Ashwood-Smith, M.J. \& Grant, E. (1977) Genetic stability in cellular systems stored in the frozen state. In Freezing of Mammalian Embryos (Ciba Fdn Symp. No. 52 (new series)), pp. 251-272. Eds K. Elliott \& J. Whelan. Elsevier, Amsterdam.

Biggers, J.D., Whitten, W.K. \& Whittingham, D.G. (1971) The culture of mouse embryos in vitro. In
Methods in Mammalian Embryology, pp. 86-116. Ed. J. C. Daniel, Jr. W. J. Freeman, San Francisco.

Dufrain, R.J. (1976) The effects of ionizing radiation on preimplantation mouse embryos developing in vitro. In Basic Aspects of Freeze Preservation of Mouse Strains, pp. 73-83. Ed. O. Mühlbock. Gustav Fischer Verlag, Stuttgart.

Dufrain, R.J. \& Casarett, A.P. (1975) Response of the pronuclear mouse embryo to $\mathrm{X}$-irradiation in vitro. Radiation Res. 63, 494-500. 
Goldstein, L.S., Spindle, A.I. \& Pedersen, R.A. (1975) Xray sensitivity of preimplantation mouse embryos in vitro. Radiation Res. 62, 276-287.

Lyon, M.F., Whittingham, D.G. \& Glenister, P.H. (1977) Long-term storage of frozen mouse embryos under increased background irradiation. In Freezing of Mammalian Embryos (Ciba Fdn Symp. No. 52 (new series)), pp. 273-290. Eds K. Elliott \& J. Whelan. Elsevier, Amsterdam.

Lyon, M.F., Glenister, P.H. \& Whittingham, D.G. (1981) Long-term viability of embryos stored under irradiation. In Frozen Storage of Laboratory Animals, pp. 139-147. Ed. G. H. Zeilmaker. Gustav Fischer Verlag, Stuttgart.

Nias, A.H.W. \& Ebert, M. (1969) Effects of single and continuous irradiation of HeLa cells at $-196^{\circ} \mathrm{C}$. Int . J. Rad. Biol. 16, 31-41.

Pedersen, R.A. \& Brandiff, B. (1981) Repair of the ultraviolet-irradiated male genome in fertilized mouse eggs. Science, N.Y. 211, 1431-1433.

Quinn, P., Barros, C. \& Whittingham, D.G. (1982)
Preservation of hamster oocytes to assay the fertilizing capacity of human spermatozoa. J. Reprod. Fert. 66, 161-168.

Roberts, E.H. (1972) Cytological, genetical and metabolic changes associated with loss of viability. In Viability of Seeds, ch. 9, pp. 253-306. Ed. E. H. Roberts. Chapman \& Hall, London.

Whittingham, D.G. (1971) Culture of mouse ova. $J$. Reprod. Fert., Suppl. 14, 7-21.

Whittingham, D.G. (1976) General aspects of egg culture and preservation. In Egg Transfer in Cattle, pp. 101116. Ed. L. E. A. Rowson. E.E.C. Commission, Luxembourg.

Whittingham, D.G., Lyon, M.F. \& Glenister, P.H. (1977) Long-term storage of mouse embryos at $-196^{\circ} \mathrm{C}$ : the effect of background radiation. Genet. Res. 29, 171181.

Whittingham, D.G., Wood, M.J., Farrant, J., Lee, H. \& Halsey, J.A. (1979) Survival of frozen mouse embryos after rapid thawing from $-196^{\circ} \mathrm{C} . J$. Reprod. Fert. 56, 11-21.

Received 26 May 1983 